\title{
Analytical Performance of an Inductively Coupled Plasma Optical Emission Spectrometry with Dual View Configuration
}

\author{
Júlio C. J. Silva ${ }^{*, a}$, Nivaldo Baccan ${ }^{a}$ and Joaquim A. Nóbrega ${ }^{b}$ \\ anstituto de Química, Universidade Estadual de Campinas, CP 6154, 13084-971 Campinas - SP, Brazil \\ ${ }^{b}$ Departamento de Química, Universidade Federal de São Carlos, CP 676, 13080-900 São Carlos - SP, Brazil
}

\begin{abstract}
O desempenho analítico de um espectrômetro de emissão óptica com plasma indutivamente acoplado configurado axial e radialmente (AX-ICP OES e RD-ICP OES, respectivamente) foi avaliado em termos da razão $\mathrm{Mg} \mathrm{II/Mg} \mathrm{I,} \mathrm{efeitos} \mathrm{de} \mathrm{matriz} \mathrm{e} \mathrm{limites} \mathrm{de} \mathrm{detecção} \mathrm{(LOD).} \mathrm{Todas} \mathrm{as}$ soluções foram preparadas em ácido nítrico $1 \% \mathrm{v} \mathrm{v}^{-1}$ ou em uma mistura de aminas terciárias solúveis em água $10 \% \mathrm{v} \mathrm{v}^{-1}$ (CFA-C), ajustada para $\mathrm{pH}$ 8. Usando uma vazão de nebulização de $0,5 \mathrm{~L} \mathrm{~min}^{-1}$ e potência aplicada de $1,3 \mathrm{~kW}$, a razão $\mathrm{Mg}$ II/Mg I foi pelo menos 15 em qualquer meio para ambas configurações. Em condições robustas, os processos do plasma praticamente não foram alterados pela presença de $0,1 \% \mathrm{~m} \mathrm{v}^{-1}$ de $\mathrm{Ca}, \mathrm{K}$ ou Na em ambas configurações. Porém, efeitos de interferência foram observados em condições não robustas, principalmente com AX-ICP OES em ambos os meios. Os melhores LOD foram obtidos usando AX-ICP OES em condições robustas e em soluções preparadas no meio contendo as aminas.
\end{abstract}

The analytical performance of axially and radially viewed inductively coupled plasma optical emission spectrometers (AX-ICP OES and RD-ICP OES, respectively) were evaluated in terms of the $\mathrm{Mg} \mathrm{II/Mg} \mathrm{I} \mathrm{ratio,} \mathrm{matrix} \mathrm{effects,} \mathrm{and} \mathrm{detection} \mathrm{limits} \mathrm{(LOD).} \mathrm{All} \mathrm{solutions} \mathrm{were} \mathrm{made} \mathrm{in} \mathrm{either}$ $1 \% \mathrm{v} \mathrm{v}^{-1}$ nitric acid or in a $10 \% \mathrm{v} \mathrm{v}^{-1}$ water-soluble tertiary amine solution (CFA-C) adjusted to $\mathrm{pH}$ 8. Using a nebulization gas flow-rate of $0.5 \mathrm{~L} \mathrm{~min}^{-1}$ and applied power of $1.3 \mathrm{~kW}, \mathrm{Mg} \mathrm{II} / \mathrm{Mg}$ I ratio was at least 15 in any medium for both configurations. Under robust conditions, plasma processes were practically not affected by the presence of $0.1 \% \mathrm{~m} \mathrm{v}^{-1}$ of $\mathrm{Ca}, \mathrm{K}$, or $\mathrm{Na}$ in both configurations. However, interference effects were observed with non-robust conditions, mainly with AX-ICP OES in both media. The best detection limits were obtained using AX-ICP OES under robust conditions, with solutions prepared in the amine medium.

Keywords: ICP OES, axial view, radial view, robustness, sensitivity, Mg II/Mg I ratio

\section{Introduction}

Inductively coupled plasma optical emission spectrometry (ICP OES) is a multi-elementar technique that allows the determination of major, minor and trace elements in complex samples. ${ }^{1}$ However, depending on the analyte and equipment configuration the detectability is lower than that typically obtained using graphite furnace atomic absorption spectrometry (GFAAS) ${ }^{2}$ and inductively coupled plasma mass spectrometry (ICP-MS). ${ }^{3}$

In the last decade this limitation was at least partially circumvented by positioning the plasma torch horizontally (i.e. axially). This configuration increases the amount of

\footnotetext{
*e-mail: jcjs@iqm.unicamp.br
}

radiation energy that reaches the entrance slit of the polychromator. Nevertheless, the consequent increase of background radiation and radiation emitted by major constituents, such as alkaline and alkaline earth elements, can increase interferences in the emission spectrum. Additionally, measurements in the cool plasma region also increase interferences caused by formation of molecular compounds and easily ionizable elements (EIE). These effects are being studied ${ }^{4-6}$ and the $\mathrm{Mg}$ II $280.2 / \mathrm{Mg}$ I 285.2 $\mathrm{nm}$ ratio is frequently used as practical criterion to evaluate analytical performance and plasma robustness, taking into account the presence of interferences, such as $\mathrm{Ca}$ and $\mathrm{Na}$. The term "robustness" is used to describe the excitation and atomization conditions in the ICP, and this occur when the Mg II/Mg I are close to LTE (local thermodynamic excitation) values $(>10)$. A robust plasma can be obtained 
when using a low nebulization gas flow-rate, an elevated radio frequency power, and a central injector tube with an internal diameter equal to or larger than $2.0 \mathrm{~mm} .{ }^{6,11}$ However, in spite of the improvement in atomizationexcitation conditions, these operational parameters can cause high background emission and poor detectability. ${ }^{4}$ On the other hand, the use of the plasma with robust conditions cannot completely guarantee the total elimination of matrix effects ${ }^{5}$ and also may compromise the signal-to-background ratio (SBR) even when the axially viewed observation mode is employed. ${ }^{?}$

The effects of nebulization gas flow-rate, radio frequency power and interference processes caused by $0.1 \% \mathrm{~m} \mathrm{v}^{-1}$ of $\mathrm{Ca}, \mathrm{K}$, or Na in nitric acid or coal fly ash - C (CFA-C) on plasma robustness were evaluated in this work. The plasma robustness was diagnosed by measuring the Mg II $280.270 \mathrm{~nm} / \mathrm{Mg}$ I $285.213 \mathrm{~nm}$ ratios. The detection limits of several elements usually found in biological samples were determined using both observation modes of ICP OES, operated under either robust or non-robust conditions.

\section{Experimental}

\section{Instrumentation}

An ICP OES model Optima 3000 DV (Dual View, Perkin Elmer, Norwalk, CT, USA) equipped with a radio frequency source (RF) of $40 \mathrm{MHz}$ incorporating a Echelle grating (79 lines $\mathrm{mm}^{-1}$ ) plus a cross dispersion optical mounting, a solid state segmented charged detector (234 SCD arrays), a Scott double-pass spray chamber, a cross-flow nebulizer and a central torch tube injector with an internal diameter of $2.0 \mathrm{~mm}$ was employed. On the axial viewing mode (AXICP OES), the cool plasma recombination area was striped off with a shear gas interface. The conditions of operation of the ICP OES are presented in the Table 1. All emission line wavelengths employed for measurements, and their characteristics, are presented in Table 2.

Table 1. Instrumental parameters

\section{Applied power $(\mathrm{kW})$}

Nebulizer gas flow-rate $\left(\mathrm{L} \mathrm{min}^{-1}\right)$

Auxiliary gas flow-rate $\left(\mathrm{L} \mathrm{min}^{-1}\right)$

Plasma gas flow-rate $\left(\mathrm{L} \mathrm{min}^{-1}\right)$

Sample aspiration flow-rate $\left(\mathrm{mL} \mathrm{min}^{-1}\right)$

Observation height ${ }^{\mathrm{a}}(\mathrm{mm})$

Background correction

Automatic integration (s)

Read (s)

Replicates

aRadial view configuration.
Table 2. Emission line wavelengths, ionization (IP) and excitation (EP) potentials ${ }^{6}$

\begin{tabular}{lcccc}
\hline Element & $\lambda(\mathrm{nm})$ & $\mathrm{IP}(\mathrm{eV})$ & $\mathrm{EP}(\mathrm{eV})$ & $\mathrm{EP}+\mathrm{IP}(\mathrm{eV})$ \\
\hline Ba II & 455.4 & 2.72 & 5.21 & 7.93 \\
$\mathrm{Al} \mathrm{I}$ & 396.1 & 5.99 & 3.14 & 9.13 \\
$\mathrm{Al} \mathrm{I}$ & 308.2 & 4.02 & 5.99 & 10.01 \\
$\mathrm{Ba}$ II & 233.5 & 6.00 & 5.21 & 11.21 \\
$\mathrm{Cu}$ I & 324.7 & 7.72 & 3.82 & 11.54 \\
Mg II & 280.2 & 7.65 & 4.42 & 12.07 \\
Mn II & 260.6 & 4.75 & 7.44 & 12.19 \\
Mn II & 257.6 & 4.81 & 7.44 & 12.25 \\
Mg I & 285.2 & 7.65 & 4.43 & 12.08 \\
Fe II & 238.2 & 7.87 & 5.22 & 13.09 \\
Mo II & 203.8 & 6.08 & 7.10 & 13.18 \\
Mo II & 202.0 & 6.13 & 7.10 & 13.23 \\
Cd I & 228.8 & 8.99 & 5.41 & 14.40 \\
Cd II & 214.4 & 8.99 & 5.78 & 14.77 \\
Cu II & 224.7 & 7.72 & 8.23 & 15.95 \\
Se I & 196.0 & 9.75 & 6.32 & 16.07 \\
\hline
\end{tabular}

\section{Solutions and reagents}

Solutions containing $10 \% \mathrm{v} \mathrm{v}^{-1}$ of several water soluble tertiary amines as reagent (CFA-C, Spectrasol, Warwick, $\mathrm{NY}$, USA) were prepared and the $\mathrm{pH}$ was adjusted to 8 using concentrated nitric acid. The $\mathrm{pH}$ of the $10 \% \mathrm{v} \mathrm{v}^{-1}$ solution is about 12 and continuous introduction of solutions prepared in this $\mathrm{pH}$ could reduce plasma torch lifetime due to increased quartz crystallization induced by alkaline solution. ${ }^{8}$ These media were evaluated because the first $\left(1 \% \mathrm{v} \mathrm{v}^{-1} \mathrm{HNO}_{3}\right)$ is usually adopted for avoiding cation hydrolysis and the last has positive effects on sample introduction and plasma characteristics. ${ }^{8,9}$

The $\mathrm{Mg}$ II/Mg I ratios were measured by using solutions containing $2 \mathrm{mg} \mathrm{L}^{-1}$ of $\mathrm{Mg}$ in $1 \% \mathrm{v} \mathrm{v}^{-1} \mathrm{HNO}_{3}$ or in $10 \% \mathrm{v} \mathrm{v}^{-1}$ CFA-C media.

Interference solutions containing $0.1 \% \mathrm{~m} \mathrm{v}^{-1}$ of $\mathrm{Ca}, \mathrm{K}$, or $\mathrm{Na}$ and also a mixed solution containing $0.1 \% \mathrm{~m} \mathrm{v}^{-1}$ of each concomitant were prepared in $\mathrm{HNO}_{3}$ or CFA-C media.

The ICP OES was calibrated using reference solutions containing $0.1,0.5,1.0$, and $2.0 \mathrm{mg} \mathrm{L}^{-1}$ prepared from secondary stock solutions containing $100 \mathrm{mg} \mathrm{L}^{-1}$ of each evaluated metal $\left(2 \% \mathrm{v} \mathrm{v}^{-1}\right.$ nitric acid medium $)$ and purified water from a Milli-Q system (Millipore, Bedford, MA, USA).

\section{Procedure}

The parameters evaluated in this study were the nebulization gas flow-rate, that was varied from 0.3 to $1.0 \mathrm{~L} \mathrm{~min}^{-1}$, and the applied power, which was varied in the 1.1-1.5 kW range. All measurements were performed in $\mathrm{HNO}_{3}$ or CFA-C media. The effect of these parameters on $\mathrm{Mg} \mathrm{II} / \mathrm{Mg}$ I ratio was systematically studied. 
Matrix effects were evaluated using the solutions described above. Measurements were carried out in both ICP OES configurations operated at robust and non-robust conditions. Again, the $\mathrm{Mg} \mathrm{II} / \mathrm{Mg}$ I ratio was adopted as the parameter to diagnose plasma conditions.

The limits of detection (LOD) measured for several analytes with a large range of involved energies (7.93 to $16.07 \mathrm{eV}$, Table 2) were calculated according to Thomsen et al. ${ }^{10}$

\section{Results and Discussion}

\section{Effect of nebulization gas flow-rate}

The effect of nebulization gas flow-rate on $\mathrm{Mg}$ II/Mg I ratio was evaluated by fixing the applied power at $1.3 \mathrm{~kW}$. Measurements were carried out in the $0.3-1.0 \mathrm{~L} \mathrm{~min}^{-1}$ range using solutions prepared in $\mathrm{HNO}_{3}$ or CFA-C.

Figure 1a shows that, in AX-ICP OES, a bell-shaped curve was obtained and the highest $\mathrm{Mg}$ II/Mg I was reached in the $0.4-0.6 \mathrm{~mL} \mathrm{~min}-1$ range for both media studied. The values around 16 and 18 in CFA-C and nitric acid media, respectively, indicate a plasma operated under robust conditions and probably less affected by interferences. These data are in agreement with literature data ${ }^{6,711}$ when plasmas were operated at low nebulization gas flow-rates
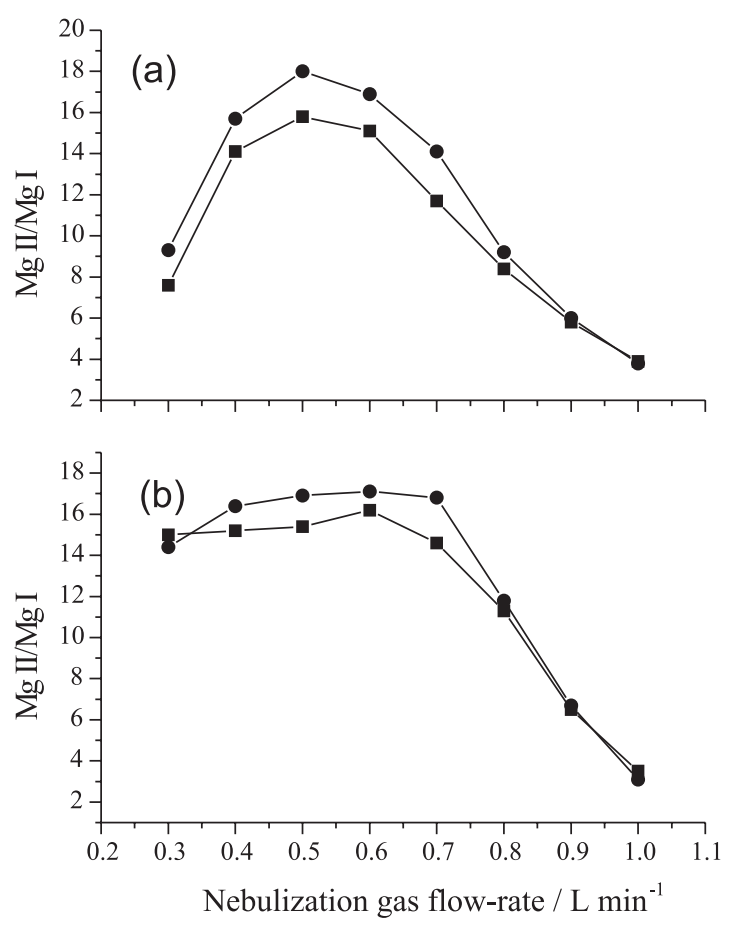

Figure 1. Effect of nebulization gas flow-rate on $\mathrm{Mg} \mathrm{II} / \mathrm{Mg} \mathrm{I}$ ratios

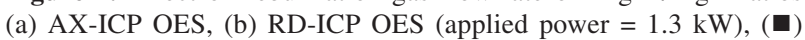
$1 \% \mathrm{v} \mathrm{v}^{-1} \mathrm{HNO}_{3}$ and $(\bullet) 10 \% \mathrm{v} \mathrm{v}^{-1} \mathrm{CFA}-\mathrm{C}$. and high applied power. According to the literature, ${ }^{6} \mathrm{Mg}$ II/Mg I ratios higher than 10 indicates a plasma with local thermodynamic equilibrium in optimum conditions of energy transfer and residence time.

On the other hand, $\mathrm{Mg}$ II/Mg I ratios were severely degraded for both media when using nebulization gas flowrates higher than $0.8 \mathrm{~L} \mathrm{~min}^{-1}$, indicating a pronounced decrease of energy transfer from plasma to sample aerosol, characterizing a plasma under non-robust conditions. ${ }^{6,12}$

The results obtained using radially viewed (RD) ICP OES are presented in Figure $1 \mathrm{~b}$. In both media, a plateau is seen in the 0.3 to $0.7 \mathrm{~L} \mathrm{~min}^{-1}$ range and, for higher flowrates, a continuous decrease of $\mathrm{Mg}$ II/ $\mathrm{Mg}$ I was observed. Slightly better values were attained in the CFA-C medium. Maximum values were similar to those obtained using AXICP OES. As expected, once again the $\mathrm{Mg}$ II/Mg I ratio decreased at higher nebulization gas flow-rates.

The main difference observed in each configuration is related to the behavior at low nebulization gas flow-rates. It could be considered that for any nebulization gas flowrate, the residence time is higher in AX-ICP OES than in RD-ICP OES, due to the longer optical path in the first configuration. This implies that in the AX-ICP OES there is more time for converting aerosol ions into atoms, excited atoms, ions, excited ions, and molecular species generated by recombination. All these processes are incremented when the nebulization gas flow-rate is decreased, resulting in a reduction of the $\mathrm{Mg} \mathrm{II} / \mathrm{Mg}$ I ratio as observed in the bellshaped curve (Figure 1a). On the other hand most of the emitted radiation is generated by ionic lines at the observation height fixed in the RD-ICP OES (15 mm). This means that high $\mathrm{Mg}$ II/Mg I ratios are attained in this configuration, compared to the axial one, owing to the occurrence of recombination processes.

\section{Effect of applied power}

The effect of applied power on plasma robustness was evaluated in CFA-C and nitric acid media. Based on the prior experiments, nebulization gas flow-rates were fixed at 0.5 and $1.0 \mathrm{~L} \mathrm{~min}^{-1}$ resulting in robust and non-robust conditions, respectively.

The applied power was varied from 1.1 to $1.5 \mathrm{~kW}$ and from 1.25 to $1.50 \mathrm{~kW}$ in nitric acid and CFA-C media, respectively. An applied power lower than $1.25 \mathrm{~kW}$ did not generate a stable plasma in the CFA-C medium.

Figures 2 and 3 show that plasma robustness was improved in both configurations when increasing the applied power. At low nebulization gas flow-rates (Figures $2 \mathrm{a}$ and $3 \mathrm{a}$ ), robust conditions were reached for all applied power in both configurations and higher $\mathrm{Mg} \mathrm{II} / \mathrm{Mg}$ I values 

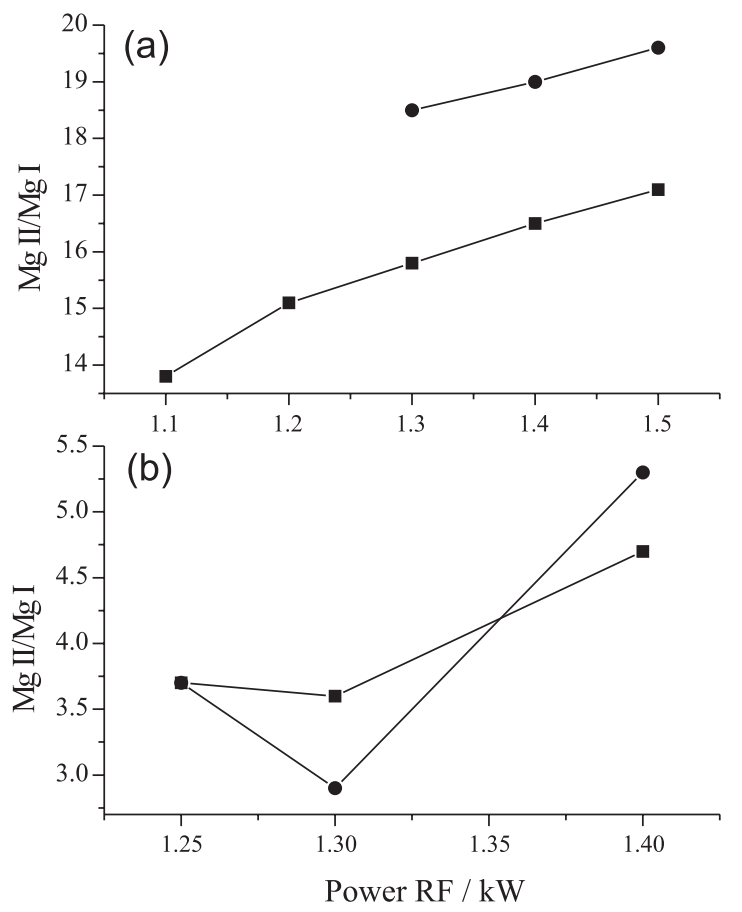

Figure 2. Effect of applied power on $\mathrm{Mg} \mathrm{II} / \mathrm{Mg}$ I ratio in the $\mathrm{AX}$ ICP OES (a) $0.5 \mathrm{~L} \mathrm{~min}^{-1}$, (b) $1.0 \mathrm{~L} \mathrm{~min}^{-1}$, (匹) $1 \% \mathrm{v} \mathrm{v}^{-1} \mathrm{HNO}_{3}$ and (•) $10 \% \mathrm{v} \mathrm{v}^{-1}$ CFA-C.

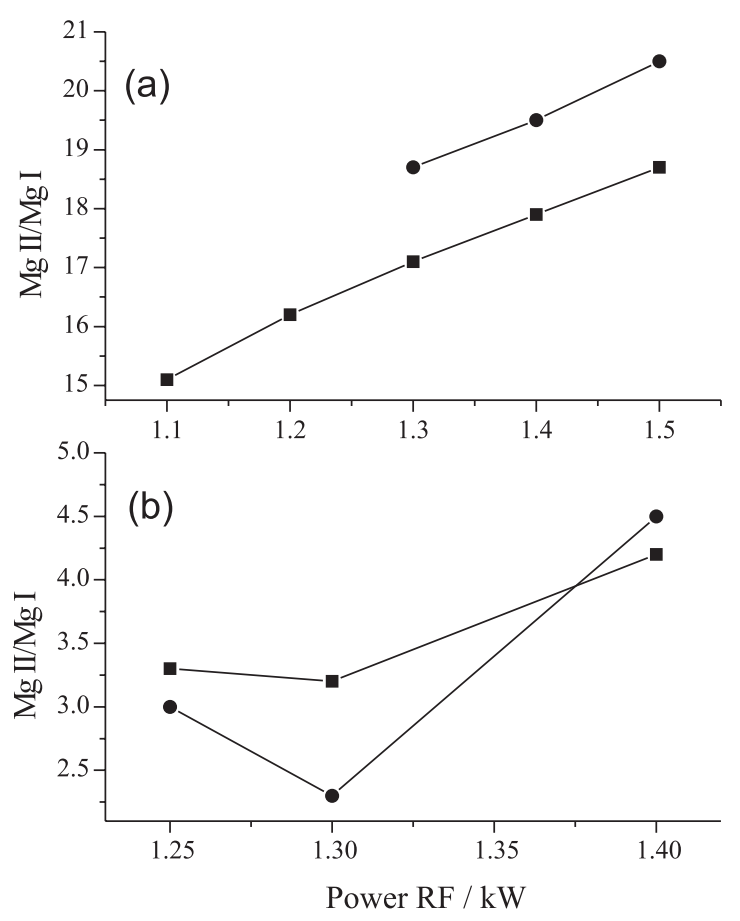

Figure 3. Effect of applied power on $\mathrm{Mg} \mathrm{II} / \mathrm{Mg}$ I ratio in the RDICP OES (a) $0.5 \mathrm{~L} \mathrm{~min}^{-1}$ and (b) $1.0 \mathrm{~L} \mathrm{~min}^{-1}$ (ष) $1 \% \mathrm{v} \mathrm{v}^{-1} \mathrm{HNO}_{3}(\bullet)$ $10 \% \mathrm{v} \mathrm{v}^{-1}$ CFA-C.

were attained in CFA-C, indicating the positive effects caused by the tertiary amine solution.

On the other hand, in both configurations, non-robust plasma was generated at a nebulization gas flow-rate of 1.0 L min ${ }^{-1}$ (Figures $2 \mathrm{~b}$ and $3 \mathrm{~b}$ ). Under this condition, nitric acid and CFA-C solutions presented very similar behavior. The lower intensities at high nebulization gas flow-rates are related to the lower residence time with this condition. It can be concluded that these conditions are not suitable for the determination of analytes in complex samples, due to the possible occurrence of interferences. ${ }^{13}$

Considering these results, it can be mentioned that the main effects of CFA-C solution occur during sample nebulization, probably due to the generation of an aerosol with lower particle sizes. This behavior can be related to formation and transport of the sample aerosol in the presence of organic compounds. According to Dubuisson et al. ${ }^{11}$ organic media frequently cause an increase of the amount of the aerosol reaching the plasma and a consequent increment of signal intensities.

It should also be mentioned that the residence time of analytes in the plasma is affected by the internal diameter of the central torch tube. This parameter exerts a critical influence on the gas velocity, and consequently, on the sample transport through the plasma. Literature data ${ }^{4-7}$ recommends a tube diameter equal to or higher than 2.0 $\mathrm{mm}$ to reach robust conditions. All data presented here were obtained using a central tube with $2.0 \mathrm{~mm}$ of internal diameter.

\section{Matrix effects}

In ICP OES with axial view configuration, emphasis is given to effects caused by alkaline and earth-alkaline elements on emission intensity measurements at low and high aerosol loadings (concentric, microconcentric, and ultrasonic nebulizers). Effects caused by these elements are generally studied because they occur as major elements in different types of samples, such as geological and biological materials, and they can modify excitation and ionization plasma conditions. ${ }^{14}$ These effects can be generated by physical processes that affect sample introduction, e.g. sample viscosity, surface tension, and effects induced by the presence of a high concentration of dissolved solids, or by modification of excitation and ionization conditions of the plasma. ${ }^{6,11}$

The results obtained using AX-ICP OES and RD-ICP OES are shown in Table 3. With robust conditions, Mg II/ $\mathrm{Mg}$ I ratio variations were lower than $22 \%$. As expected, robust conditions caused an attenuation of influence induced by EIE on emission intensities. Similar results were previously presented by Brenner et al. ${ }^{7}$ and Garcia et $a l .{ }^{5} \mathrm{~A}$ distinct behavior was observed in non-robust conditions, with variations as high as $52 \%$. The data 
presented did not allow the evaluation of the source of depressive effects, i.e. sample introduction system or plasma conditions.

Employing robust conditions, the results obtained using RD-ICP OES (Table 3), shown that the Mg II/Mg I ratios remained practically constant, i.e. variations lower than $2 \%$, independent of the presence of any concomitant. On the other hand, when using a nebulization gas flowrate of $1.0 \mathrm{~L} \mathrm{~min}^{-1}$, the $\mathrm{Mg} \mathrm{II/Mg}$ I ratios were 3.8 or lower than 2.9, without or with concomitants in the solution, respectively. These values indicate a condition of nonrobust plasma operation and consequent susceptibility to matrix interferences.

Table 3. Effects caused by concomitants $\left(0.1 \% \mathrm{~m} \mathrm{v}^{-1}\right.$ in nitric acid or CFA-C) on plasma robustness: AX-ICPOES and RD-ICP OES

\begin{tabular}{|c|c|c|c|c|}
\hline \multirow{3}{*}{ Mg II/Mg I } & \multicolumn{2}{|c|}{ Robust conditions $\mathrm{s}^{\mathrm{a}}$} & \multicolumn{2}{|c|}{ Non-robust conditions ${ }^{b}$} \\
\hline & $1 \%$ & $10 \%$ & $1 \%$ & $10 \%$ \\
\hline & $\mathrm{HNO}_{3}$ & CFA-C & $\mathrm{HNO}_{3}$ & CFA-C \\
\hline \multicolumn{5}{|l|}{ Axial viewed } \\
\hline - & 10.3 & 10.3 & 4.4 & 3.5 \\
\hline $\mathrm{Ca}$ & 8.8 & 8.8 & 3.1 & 2.2 \\
\hline K & 8.6 & 8.8 & 3.1 & 2.3 \\
\hline $\mathrm{Na}$ & 8.5 & 9.0 & 2.8 & 2.0 \\
\hline $\mathrm{Ca}, \mathrm{K}, \mathrm{Na}$ & 8.0 & 8.4 & 2.4 & 1.7 \\
\hline \multicolumn{5}{|c|}{ Radial viewed } \\
\hline- & 9.8 & 10.0 & 3.8 & 3.8 \\
\hline $\mathrm{Ca}$ & 9.6 & 9.7 & 2.7 & 2.7 \\
\hline $\mathrm{K}$ & 9.8 & 9.9 & 2.9 & 2.9 \\
\hline $\mathrm{Na}$ & 9.8 & 10.0 & 2.7 & 2.7 \\
\hline $\mathrm{Ca}, \mathrm{K}, \mathrm{Na}$ & 9.6 & 9.8 & 2.5 & 2.5 \\
\hline
\end{tabular}

a Nebulization gas flow-rate: $0.5 \mathrm{~L} \mathrm{~min}^{-1}$ and applied power: $1.3 \mathrm{~kW}$;

${ }^{\mathrm{b}}$ Nebulization gas flow-rate: $1.0 \mathrm{~L} \mathrm{~min}^{-1}$; and applied power: $1.3 \mathrm{~kW}$.
Different behaviors were observed in both configurations with robust conditions. Since axial and radial measurements are carried out using a dual view equipment, it can be concluded that the reduction of $\mathrm{Mg}$ II/ $\mathrm{Mg}$ I ratios in the AX-ICP OES is not related to the sample introduction system, but to processes occurring in the plasma affected by the energy consumed by dissociation, atomization, and excitation of matrix species. ${ }^{6,7}$

\section{Limits of Detection}

All limits of detection (LOD) obtained using both plasma configurations are shown in Table 4. All results are based on an applied power of $1.3 \mathrm{~kW}$ and nebulizer gas flow-rates of 0.5 and $0.8 \mathrm{~L} \mathrm{~min}^{-1}$.

The degradation of LOD when operating the plasma under robust conditions was not so large, compared to the values obtained with non-robust conditions. This is an indication that the shear gas interface seems to attenuate the entrance of background radiation in the polychromator and this avoids a deterioration of BEC values.

Comparing the LOD estimated for nitric acid and for CFA-C media, it can be seen that, in general, lower values were obtained in the amines medium (Table 4). This observation corroborates the previous discussion about the positive effects of the amine solution on sample introduction. According to Stewart et al., ${ }^{15}$ nitric acid affects mainly the properties of the tertiary aerosol (smaller drops) rather than the primary aerosol (bigger drops). Thus the influence of the acid medium on the aerosol transport probably occurred due to changes in the net density and evaporation rate of the aerosol. In an organic medium, the

Table 4. Limits of detection $\left(\mu \mathrm{g} \mathrm{L}^{-1}\right)$ in $1 \% \mathrm{v} \mathrm{v}^{-1}$ nitric acid and $10 \% \mathrm{v} \mathrm{v}^{-1}$ CFA-C with AX-ICP OES and RD-ICP OES

\begin{tabular}{|c|c|c|c|c|c|c|c|c|c|c|}
\hline \multirow{3}{*}{ Element } & \multirow{3}{*}{$\lambda(\mathrm{nm})$} & \multirow{3}{*}{$\mathrm{IP}+\mathrm{EP}(\mathrm{eV})$} & \multicolumn{4}{|c|}{ Axial viewed } & \multicolumn{4}{|c|}{ Radial viewed } \\
\hline & & & \multicolumn{2}{|c|}{ Robust condition $^{\mathrm{a}}$} & \multicolumn{2}{|c|}{ Non robust condition ${ }^{b}$} & \multicolumn{2}{|c|}{ Robust condition $^{a}$} & \multicolumn{2}{|c|}{ Non robust condition ${ }^{b}$} \\
\hline & & & $\mathrm{HNO}_{3}$ & CFA-C & $\mathrm{HNO}_{3}$ & CFA-C & $\mathrm{HNO}_{3}$ & CFA-C & $\mathrm{HNO}_{3}$ & CFA-C \\
\hline $\mathrm{Ba}$ II & 455.4 & 7.93 & 0.2 & 0.2 & 1.4 & 2.1 & 1.2 & 2.1 & 0.9 & 0.5 \\
\hline Al I & 396.3 & 9.13 & 8.8 & 8.3 & 4.3 & 4.4 & 77.4 & 92.4 & 8.4 & 26.6 \\
\hline Al I & 308.2 & 10.01 & 28.2 & 14.7 & 26.8 & 22.0 & 93.9 & 133.9 & 55.0 & 61.7 \\
\hline $\mathrm{Ba}$ II & 233.5 & 11.21 & 0.1 & 0.8 & 0.9 & 1.9 & 5.6 & 9.3 & 3.8 & 7.5 \\
\hline $\mathrm{Cu} \mathrm{I}$ & 324.7 & 11.54 & 3.9 & 2.3 & 3.1 & 2.3 & 13.8 & 8.0 & 4.5 & 5.0 \\
\hline Mn II & 260.6 & 12.19 & 0.6 & 0.5 & 0.6 & 0.6 & 3.0 & 2.5 & 3.1 & 2.3 \\
\hline Mn II & 257.6 & 12.25 & 0.6 & 0.3 & 0.6 & 0.4 & 1.0 & 1.4 & 1.1 & 1.2 \\
\hline $\mathrm{Fe}$ II & 238.2 & 13.09 & 21.9 & 5.9 & 7.5 & 10.3 & 42.4 & 14.4 & 18.0 & 11.9 \\
\hline Mo II & 203.8 & 13.18 & 6.9 & 6.9 & 12.0 & 11.2 & 52.5 & 55.0 & 84.1 & 92.5 \\
\hline Mo II & 202.0 & 13.23 & 5.6 & 6.0 & 8.5 & 5.7 & 40.7 & 65.4 & 50.4 & 85.0 \\
\hline Cd I & 228.8 & 14.40 & 1.5 & 1.1 & 1.8 & 2.0 & 11.0 & 7.5 & 10.4 & 4.6 \\
\hline Cd II & 214.4 & 14.77 & 0.6 & 0.4 & 1.8 & 1.9 & 3.9 & 4.0 & 4.3 & 6.7 \\
\hline $\mathrm{Cu} \mathrm{II}$ & 224.7 & 15.95 & 2.8 & 3.1 & 3.5 & 4.4 & 43.2 & 22.1 & 23.5 & 21.9 \\
\hline Se I & 196.0 & 16.07 & 25.3 & 19.4 & 17.7 & 28.3 & 121.4 & 193.2 & 116.2 & 199.5 \\
\hline
\end{tabular}

a Nebulization gas flow-rate: $0.5 \mathrm{~L} \mathrm{~min}^{-1}$, applied power: $1.3 \mathrm{~kW}$; ${ }^{\mathrm{b}}$ Nebulization gas flow-rate: $0.8 \mathrm{~L}$ min ${ }^{-1}$, applied power: $1.3 \mathrm{~kW}$. 
primary aerosol generated can be finer than that obtained from aqueous medium. This effect is related to the lower surface tension and higher volatility that can provide a higher loading of sample aerosol to the plasma, improving the signal intensities. ${ }^{11}$

The same operational conditions were adopted for obtaining the limits of detection in RD-ICP OES (Table 4). As expected the LOD for most elements using radial view measurements were higher than those measured with the axial view configuration. Once again, for some elements lower LOD were obtained in CFA-C solution.

\section{Conclusions}

In the presence of EIE the $\mathrm{Mg}$ II/Mg I ratio decreased under non-robust conditions in both plasma configurations and in the two media evaluated. These effects can be explained by changes in aerosol generation and transport, and atomization-excitation conditions in the plasma.

Employing robust conditions, it was demonstrated that plasma conditions remained constant in the presence of EIE in the radial view configuration and plasma changes were lower than $22 \%$ in the axial view configuration, according to the diagnosis based on $\mathrm{Mg}$ II/Mg I. This behavior is an indication that interference processes are related to changes in atomization-excitation plasma conditions when EIE are present.

The best LOD were obtained in CFA-C medium using the AX-ICP OES. This seems to be related to physical effects on sample aerosol formation and transport.

Considering the performance of the AX-ICP OES, this configuration allowed an improvement of LOD without serious degradation of matrix effects. Thus it can be concluded that this arrangement is suitable for the determination of trace analytes in complex samples when robust conditions are adopted. This conclusion is in agreement with a recent statement proposed by Brenner and Zander ${ }^{6}$ suggesting that robust axially-viewed ICP can be used in a wide range of analytical applications, possibly overcoming the need for radial setups or for configurations having both axial and radial viewing capabilities.

\section{Acknowledgements}

The authors express their gratitude to the Scientific Committee of the XI Encontro Nacional de Química
Analítica, held at Instituto de Química of the Universidade Estadual de Campinas (September, 2001) for the kind invitation to prepare this article. The authors are also grateful to CNPq and FAPESP by research support. J.C.J.S would like to thank FAPESP for a doctorate fellowship. J.A.N thanks CNPq for a researchship.

\section{References}

1. Masson, P.; Orignac, D.; Vives, A.; Prunet, T.; Analusis 1999, $27,813$.

2. Gasparics, T.; Martinez, R. M. G.; Caroli, S.; Zaray, G.; Microchem. J. 2000, 67, 279.

3. Ryan, A.; ICP-21, (Varian) 1997, 1.

4. Brenner, I. B.; Zander, A.; Cole, M.; Wiseman, A.; J. Anal. At. Spectrom. 1997, 12, 897.

5. Garcia, E. E.; Nogueira, A. R. A.; Nobrega, J. A.; J. Anal. At. Spectrom. 2001, 16, 825.

6. Brenner, I. B.; Zander, A. T.; Spectrochim. Acta 2000, B 55, 1195.

7. Brenner, I. B.; Zischka, M.; Maichin, B.; Knapp, G.; J. Anal. At. Spectrom. 1998, 13, 1257.

8. Nobrega, J. A.; Gélinas, Y.; Krushevska A.; Barnes, R. M.; J. Anal. At. Spectrom. 1997, 12, 1243.

9. Nobrega, J. A.; Gelinas, Y.; Krushevska, A.; Barnes, R. M.; J. Anal. At. Spectrom. 1997, 12, 1239.

10. Thomsen, V.; Roberts, G.; Burgess, K.; Spectroscopy 2000 , $33,33$.

11. Dubuisson, C.; Poussel, E.; Todoli, J. L.; Mermet J. M; Spectrochim. Acta 1998, B 53, 593.

12. Stepan, M.; Musil, P.; Poussel, E.; Mermet, J. M.; Spectrochim. Acta 2001, B 56, 443.

13. Dennaud, J.; Howes, A.; Poussel, E.; Mermet, J. M.; Spectrochim. Acta 2001, B 56, 101.

14. Dubuisson, C.; Poussel, E.; Mermet, J. M.; Todoli, J. L.; J. Anal. At. Spectrom. 1998, 13, 63.

15. Stewart, I. I.; Olesik, J. W.; J. Anal. At. Spectrom. 1998, 13, 1249.

Received: October 19, 2002

Published on the web: March 28, 2003

FAPESP helped in meeting the publication costs of this article. 